\title{
Taste, traits, and tendencies
}

\author{
Alexander Dinges ${ }^{1} \cdot J_{u l i a}$ Zakkou $^{2}$
}

\begin{abstract}
Many experiential properties are naturally understood as dispositions such that e.g. a cake tastes good to you iff you are disposed to get gustatory pleasure when you eat it. Such dispositional analyses, however, face a challenge. It has been widely observed that one cannot properly assert "The cake tastes good to me" unless one has tried it. This acquaintance requirement is puzzling on the dispositional account because it should be possible to be disposed to like the cake even if this disposition has never been manifested. We argue that familiar response strategies on behalf of the dispositionalist fail. These include appeals to conversational implicatures, expressivism, semantic presuppositions and norms of assertion. Against this background, we propose a new analysis in terms of what we call tendencies, where a tendency is a disposition that has been manifested. The acquaintance requirement comes out as an entailment. We point out a hitherto unnoticed parallel to sentences ascribing character traits such as "Hannah is brave," and extend our tendency-based analysis to this domain.
\end{abstract}

Keywords Predicates of personal taste - Acquaintance inference - Acquaintance requirement $\cdot$ Dispositions $\cdot$ Character traits

Alexander Dinges

alexander.dinges@fau.de

Julia Zakkou

julia.zakkou@fu-berlin.de

1 Institut für Philosophie, Friedrich-Alexander-Universität Erlangen-Nürnberg, Bismarckstr. 1, 91054 Erlangen, Germany

2 Institut für Philosophie, Freie Universität Berlin, Habelschwerdter Allee 30, 14195 Berlin, Germany 


\section{Introduction}

What is it for something to taste good to someone? What is it, for instance, for a cake to taste good to you? It is very natural to appeal to dispositions in response. The cake tastes good to you iff you are disposed to get gustatory pleasure when you eat it (roughly). ${ }^{1}$ Now consider what it takes for you to properly assert

(1) The cake tastes good to me.

Whatever you know about the ingredients of the cake or about other people's reactions to the cake, this assertion seems problematic unless you've tried the cake. If you haven't tried the cake, you should rather say things like

(2) The cake might/will/would taste good to me. ${ }^{2}$

On the dispositional analysis, this acquaintance requirement seems puzzling. Dispositions can be had even if they have never been manifested. For instance, a vase can be breakable even if it never breaks. It should thus be possible to have a disposition to get gustatory pleasure from eating the cake even if you've never actually had these experiences and, hence, even if you've never tried the cake. So why can't you properly assert that the cake tastes good to you when you haven't tried it?

Similar puzzles arise for a number of predicates from the experiential domain. In each case, an acquaintance requirement clashes with an otherwise plausible dispositional analysis. Our example above involved an explicitly relativized predicate of personal taste, a relativized PPT, for short. Acquaintance requirements also appear with bare PPTs, as in

(3) The cake tastes good. ${ }^{3}$

We find analogous requirements in the much broader class of appearance predicates, whether we complement these predicates with descriptive or with evaluative terms.

(4) The cake tastes salty/good (to me).

(5) The table looks red/beautiful (to me).

(6) The perfume smells floral/nice (to me).

Proper assertions of (4), (5) and (6) all seem to require first-personal contact with the object in question. ${ }^{4}$ Turning to aesthetic predicates, the eminent "acquaintance principle" states that "judgements of aesthetic value [...] must be based on firsthand experience of their object" (Wollheim 1980: 233). For instance, you cannot

\footnotetext{
1 See e.g. Egan (2014: §5), Ninan (2014: 307) and Anthony (2016: 697-698).

2 See e.g. Bylinina (2017: 300-301) and Anand and Korotkova (2018: 59).

3 See e.g. Pearson (2013: 117), Klecha (2014: 451), MacFarlane (2014: 3), Ninan (2014: 290-291), Bylinina (2017: 300), Anand and Korotkova (2018: 55-56) and Franzén (2018: 669).

4 See e.g. Pearson (2013: 118), Ninan (2014: 291) and Rudolph (2020: 207).
} 
properly assert (7) or (8) unless you have seen the Sagrada Familia or read Moby Dick.

(7) The Sagrada Familia is stunning.

(8) Moby Dick is moving.

Similarly, it seems that you cannot properly apply predicates of adoration to perceptual qualities when you haven't witnessed these qualities.

(9) I like (the taste of) the cake.

(10) I love (the sound of) Bach sonatas. ${ }^{5}$

Acquaintance also seems required to properly express subjective attitudes towards the presence of descriptive and evaluative perceptual qualities, as in

(11) I find the cake salty/tasty.

(12) I find this picture colorful/beautiful. ${ }^{6}$

Assertions of all these sentences seem to require acquaintance, and yet it would be natural to analyze them dispositionally. This creates a tension, which needs to be resolved.

Surprisingly, the puzzle here is not restricted to the experiential domain. These further parallels have gone unnoticed, and they place important constraints on any adequate account. Consider ascriptions of character traits, as in

(13) Hannah is brave.

Once more, it is exceedingly natural to analyze such statements dispositionally. Hannah is brave iff she is disposed to act bravely when a situation calls for bravery (roughly). ${ }^{7}$ At the same time, it seems problematic to assert (13) unless Hannah has acted bravely at least once before. When this condition isn't met, you should rather say things like

(14) Hannah might/will/would be brave. ${ }^{8}$

Why should this requirement be in place when braveness is just a disposition?

In this paper, we suggest a novel and unified solution to these puzzles. The basic idea is to abandon the dispositional analysis in favor of an analysis based on tendencies, where a tendency is understood as a disposition that has been manifested before. The acquaintance requirement comes out as an entailment of the proposition expressed.

Our discussion begins in the experiential domain. After outlining some semantic background assumptions (Sect. 2), we assess dispositionalist attempts to explain the acquaintance requirement (Sect. 3). We specifically discuss the ideas that assertions

\footnotetext{
5 See e.g. Chomsky (1972: 191), Budd (2003: 392) and Franzén (2018: 676).

6 See e.g. Bylinina (2017: 300) and Anand and Korotkova (2018: 56).

7 See e.g. Miller (2014: 18n41) for this idea and further references.

8 See e.g. Hampshire (1953: 6), Alston (1970: 62), Brandt (1970: 26) and Alvarez (2017a: 79, b: 127-128).
} 
of sentence (1) conversationally implicate, express, semantically presuppose or epistemically require that the speaker has tried the cake. Accounts along these lines have been suggested in the literature, but we find them wanting. Against this background, we present and defend our tendency account (Sect. 4). Elaborating on a proposal from Alvarez (2017a), we go on to show that analogous considerations favor a tendency-based analysis of character traits (Sect. 5).

Within the experiential domain, we focus on relativized PPTs throughout the subsequent discussion. This is primarily for methodological reasons. Most of the other predicates mentioned above create independent noise due to their controversial semantics. Relativized PPTs, meanwhile, are comparatively well understood, allowing us to study the acquaintance requirement in otherwise ideal circumstances. Given the complexity of the data surrounding the acquaintance requirement, one can only benefit from this simplification (some important disanalogies to bare PPTs remain to be explored; see e.g. footnotes 27, 30 and 34).

\section{Semantic background assumptions}

In this section, we lay out some semantic background assumptions. They account for some phenomena related to the acquaintance requirement, and thereby help us to focus on the genuinely puzzling cases.

We assume an ambiguity in our sentence (1) between what we will call a stative reading and an episodic reading. ${ }^{9}$ The stative reading seems most prominent out of context, and it is forced in the following sentence.

The cake tastes good to me. I tried it yesterday.

For this sentence to be true, the speaker has to be in some kind of state of liking the cake, but she doesn't have to be eating and enjoying the cake as she speaks. This contrasts with the following sentence.

(16) The cake tastes good to me right now.

Here the speaker plausibly refers to a specific present episode of eating and enjoying the cake.

This ambiguity may be clearer in past tense and future tense sentences such as

The cake will taste good to me.

(18) The cake tasted good to me.

In these sentences, the stative reading is triggered when we consider changes in either the food in question or our taste. It features prominently in the following sentences.

(19) The cake will taste good to me once we've added the sugar coating.

(20) The cake tasted good to me before it went off.

\footnotetext{
${ }_{9}$ Anthony (2016) discusses this ambiguity in detail and notes a parallel to the episodic/habitual ambiguity in eventive verb phrases. See also Cappelen and Hawthorne (2009: 113n21).
} 
(21) After the surgery, the cake will taste good to me.

(22) Before the surgery, the cake tasted good to me.

These sentences express, very roughly, that the speaker had or will come to have a certain kind of standing property, such as the property of receiving gustatory pleasure when eating the cake. The episodic reading, meanwhile, is triggered when we envisage specific episodes of eating the cake as in

(23) The cake is done, and when I dig in tomorrow, it will taste good to me.

(24) I had a piece of the cake yesterday. It tasted good to me.

These latter sentences seem to describe specific future or past episodes of the cake causing gustatory pleasure.

Notice here that there is an orthogonal distinction between sentences referring to a type of food (e.g. a type of cake) and sentences referring to a token of a given type of food (e.g. a token cake). We focus exclusively on token sentences in this paper. The stative-episodic ambiguity remains.

Following Anthony (2016), we want to capture the stative-episodic ambiguity in event-semantic terms along the following lines. The term "tastes good to" expresses a three-place relation between a taster, $t$, a food, $f$, and an event, e. This relation holds between $\mathrm{t}$, $\mathrm{f}$ and $\mathrm{e}$ iff $\mathrm{e}$ is an event of $\mathrm{f}$ causing gustatory pleasure in $\mathrm{t}$ (roughly). We assume that present tense taste sentences on their stative reading have the covert event variable bound by a quantifier along the following lines.

The cake tastes good to me. $(=(1))$

$\mathrm{Q}[\mathrm{r}(\mathrm{e})$; tastes-good-to(the cake, me, e)]

Here, $\mathrm{Q}$ and $\mathrm{r}$ function as metavariables for a quantifier over events e and a restriction on the domain of quantification. Depending on your preferred metaphysics of taste, you will want to replace them in different ways. Dispositionalists, for instance, will replace them in such a way that (1) ends up ascribing a relevant disposition, and they will defer to the most promising theory of dispositions for details (see below). Turning to the episodic reading, present tense taste sentences on this reading have the covert event variable contextually satisfied along the following lines.

(26) The cake tastes good to me. $(=(1))$

Tastes-good-to(the cake, me, $\mathrm{e}_{\text {now }}$ )

$\mathrm{e}_{\text {now }}$ is an event of the cake causing gustatory pleasure in me.

Here $e_{n o w}$ is a salient present, actual event, typically an event of eating the cake.

Analogous things can be said about future and past tense sentences. On their stative reading, the event variable is bound by a quantifier, which is respectively restricted to future or past events.

The cake will taste good to me. (= (17))

$\mathrm{Q}[\mathrm{e}$ is in the future, ...; tastes-good-to(the cake, me, e)]

The cake tasted good to me. (= (18))

$\mathrm{Q}[\mathrm{e}$ is in the past, ...; tastes-good-to(the cake, me, e)] 
As before, different theorists will offer different interpretations of the quantifier and the domain restriction. Dispositionalists, for instance, will assume a quantifier and a restrictor such that (27) and (28) ascribe future or past dispositions. On the episodic reading, the covert event variable is once more contextually satisfied, where $\mathrm{e}_{\text {fut }}$ and $\mathrm{e}_{\text {past }}$ are contextually salient, actual future or past events.

(29) The cake will taste good to me. (= (17))

Tastes-good-to(the cake, me, $\mathrm{e}_{\text {fut }}$ )

$\mathrm{e}_{\text {fut }}$ is an event of the cake causing gustatory pleasure in me.

The cake tasted good to me. $(=(18))$

Tastes-good-to(the cake, me, $\mathrm{e}_{\text {past }}$ )

$e_{\text {past }}$ is an event of the cake causing gustatory pleasure in me.

Sketchy as these considerations may be, they already help to explain some aspects of the acquaintance requirement. Take our familiar future and past tense taste sentences (17) and (18). The future tense sentence doesn't seem to require previous acquaintance, but it does seem to require acquaintance in the future, as the oddness of the following sentence attests.

The cake will taste good to me, but I'm not going to try it.

Better: The cake would taste good to me, but I'm not going to try it.

The past tense sentence similarly requires acquaintance in the past, as seen by the oddness of

(32) The cake tasted good to me, I didn't try it though.

Better: The cake would have tasted good to me; I didn't try it though.

If we focus on the episodic readings, we are already in a position to explain this. The propositions that $\mathrm{e}_{\text {fut }}$ and $\mathrm{e}_{\text {past }}$ are events of the cake causing gustatory pleasure in the speaker more or less trivially entail that $\mathrm{e}_{\text {fut }}$ and $\mathrm{e}_{\text {past }}$ are events of the speaker trying the cake. After all, this is how food causes gustatory reactions. Since $\mathrm{e}_{\text {fut }}$ is in the future and $e_{\text {past }}$ is in the past, and given that these events are actual, it follows that there will be or were events of the speaker trying the cake and hence that the speaker will try or has tried the cake. Thus, the propositions expressed by (17) and (18) entail future or past acquaintance, and acquaintance requirements arise for this reason. For the same reason, our familiar present tense taste sentence (1) has at least one reading, the episodic reading, where it entails that the speaker is tasting the cake as she speaks. On the episodic reading, (1) expresses the proposition that $\mathrm{e}_{\text {now }}$ is an event of the cake causing gustatory pleasure in the speaker, which can be the case only if the speaker is currently tasting the cake.

In what follows, we will set aside taste sentences in contexts where they receive an episodic reading, for we think that the acquaintance requirement in such contexts is sufficiently explained in the indicated way. Acquaintance requirements also arise on the stative reading, though, and this phenomenon will be the focus of the subsequent discussion. 


\section{Dispositional accounts and why they fail}

As indicated, many authors believe that taste sentences ascribe dispositions on their stative reading (see footnote 1). These authors will thus interpret our quantifier $\mathrm{Q}$ and our restrictor $r$ such that we get truth-conditions along the following lines.

The cake tastes good to me. $(=(1))$

DISP[disp(e); tastes-good-to(the cake, me, e)]

I'm disposed to get gustatory pleasure when I eat the cake.

There is a question of how to interpret the quantifier DISP and the restrictor disp, and the details depend on which theory of dispositions one adopts. On a simple counterfactual analysis of dispositions, for instance, the quantifier will be universal. Meanwhile, the restrictor will look at the nearest possible worlds where the speaker is presently eating the cake, and it will include all present events of the speaker eating the cake in these worlds. More sophisticated analyses of dispositions may weaken the quantifier (e.g. from "all" to "generally," "most," "many" or "some") and widen the restriction (e.g. to include events from more distant worlds or events other than events of eating the cake), but we won't take a stand on this here. ${ }^{10}$ The important point is that all dispositionalists will agree that the proposition expressed by (1) doesn't entail that the speaker has tried the cake. This commitment raises the question of why you cannot properly assert (1) unless you have tried the cake.

In what follows, we'll discuss various potential answers. We'll argue that all available accounts face concerns, which will eventually lead us to abandon the dispositional analysis. For brevity, we will use TRIED to denote the proposition that the speaker has tried the cake, i.e. the content of the acquaintance requirement on assertions of (1).

\subsection{The implicature account}

Let's begin with what we'll call the implicature account of the acquaintance requirement. According to this account, TRIED is a conversational implicature of utterances of (1), and speakers of (1) are required to ensure the truth of TRIED because one shouldn't implicate falsehoods. ${ }^{11}$

The implicature account is a natural place to start, but it leads to immediate problems. One problem concerns cancellability. ${ }^{12}$ Conversational implicatures are standardly assumed to be cancellable in the sense that if an utterance of " $p$ "

\footnotetext{
${ }^{10}$ See e.g. Manley and Wasserman (2008) for discussion of a simple counterfactual analysis of dispositions, and a replacement with quantificational force in terms of "suitable proportions" that, when applied to our cases, looks at cake eating events in more than just the nearest worlds. See Vetter (2015) for a view of dispositions in terms of existential quantification with no restriction to events of eating the cake.

${ }^{11}$ Such a view is hinted at by Mothersill (1984: 159-160), Budd (2003: 391); Hopkins (2000: 217, 2011: $145)$ and Simion (2016: 3051-3052) in connection with aesthetic predicates.

12 See e.g. Ninan (2014: 296) and Franzén (2018: 671) for this worry in the domain of aesthetic predicates and bare PPTs.
} 
conversationally implicates that $q$, then sentences of the form " $p$, but not-q" or " $p$, but I don't mean to suggest that q" sound fine (Grice 1989: 39; Zakkou 2018). The following sentence, however, sounds problematic.

(34) The cake tastes good to me, but I haven't tried it.

The alleged implicature thus fails the cancelability test, which is evidence against the implicature account.

Second, the acquaintance requirement doesn't seem restricted to the linguistic domain but arises at the level of thought as well. When you haven't tried the cake, it seems not only problematic to assert that the cake tastes good to you. Outright belief in this proposition seems problematic too. When you haven't tried the cake, should rather believe that the cake would or will taste good to you. ${ }^{13}$ Proponents of the implicature account are in trouble because conversational implicatures arise in conversations, not in solitary thought (pace Douven 2010).

\subsection{The expressivist account}

Consider next what we'll call the expressivist account of the acquaintance requirement. According to this view, utterances of (1) express a positive gustatory reaction to eating the cake. More specifically, utterances of (1) aren't sincere unless the speaker had that gustatory reaction to the cake. Speakers of (1) are thus required to ensure the truth of TRIED because they would otherwise be insincere, expressing a mental state they've never had. ${ }^{14}$

The expressivist account handles the cancellability concern because sincerity conditions cannot be cancelled (Franzén 2018: 679). The problem of an acquaintance requirement at the level of belief presumably remains, for it is hard to make sense of sincerity conditions at the level of belief (see Franzén 2018: 680-681 though).

As a further concern, consider third-personal taste sentences. Suppose Hannah hasn't tried the cake, but you say,

The cake tastes good to Hannah.

In this context, (35) sounds problematic to more or less the same extent that our sentence (1) does when the speaker hasn't tried the cake. Third-personal sentences like (35) thus seem subject to an acquaintance requirement on the third party. ${ }^{15}$ The expressivist account makes this puzzling. After all, utterances of (35) no longer

\footnotetext{
13 See Hopkins (2000: 217-218, 2011: 145-146) and Budd (2003: 391) for related intuitions regarding aesthetic predicates. For opposing intuitions in the domain of aesthetic predicates and bare PPTs, see Franzén (2018: 673). These latter intuitions may result from an interpretation of "belief" as something other than outright belief (see e.g. Wedgwood 2012: 310-312 for characteristics of this latter notion).

14 Franzén (2018) puts forward a view along these lines for bare PPTs and aesthetic predicates. See also Scruton (1998: 49), Hopkins (2001: 176) and Willer and Kennedy (Forthcoming). To be sure, we doubt that these authors would want to extend their views to relativized PPTs. We want to explore this option nonetheless, to safely set it aside.

15 See Anand and Korotkova (2018: 62-63) for a related observation for bare PPTs in exocentric contexts.
} 
express an affective state. The speaker of (35) neither expresses an affective state of hers-(35) can be uttered independently of whether the speaker likes the cake. Nor does she express an affective state on the part of Hannah-it seems impossible in general to express other people's affective states.

Some supplementary story could be told about how the acquaintance requirement arises in third-person cases, independently of appeals to the expression of affective states. But any account we can think of here straightforwardly carries over to the acquaintance requirement on (1), making the expressivist account an idle wheel.

\subsection{The presupposition account}

The presupposition account of the acquaintance requirement construes TRIED as a semantic presupposition of (1) (or a conventional implicature; the subsequent considerations should apply mutatis mutandis; see similarly Ninan 2014: 299n17). According to this account, speakers of (1) must ensure the truth of TRIED because one shouldn't presuppose falsehoods. ${ }^{16}$

The presupposition account easily handles the previous data. Semantic presuppositions aren't cancellable, they arguably arise at the level of thought too, and it seems entirely coherent to assume that the alleged presupposition is sensitive to the overtly supplied subject and thus that third-personal sentences presuppose acquaintance on the part of the third party. The presupposition account further makes correct predictions for embeddings under negation (see below), and it plausibly passes a range of other familiar presupposition tests. ${ }^{17}$

The main worry we see for the presupposition account is that the alleged presupposition doesn't survive in embeddings where presuppositions standardly do survive. ${ }^{18}$ The sentence "Hannah quit smoking," for instance, arguably presupposes that Hannah smoked, and the following sentences continue to convey this message.
a. If Hannah has quit smoking, then she has a strong will.
b. Hannah might have quit smoking.
c. Has Hannah quit smoking?

We would thus expect the following sentences to similarly retain the alleged presupposition that the speaker and, respectively, Hannah have tried the cake.
a. If the cake tastes good to me, then I'm no exception.
a'. If the cake tastes good to Hannah, then she's no exception.
b. The cake might taste good to me.
b'. The cake might taste good to Hannah.

\footnotetext{
16 Chomsky (1972: 191) gestures towards a presupposition account in the domain of predicates of appreciation. See Pearson (2013: 142-143) for a presupposition account as applied to bare PPTs.

17 Ninan (2014: 296-297) points this out with respect to bare PPTs. He still rejects the presupposition account for other reasons. See below.

18 See Ninan (2014: 298-299) and Franzén (2018: 671-672) for related worries with presupposition accounts for aesthetic predicates and bare PPTs.
} 
c. Does the cake taste good to me?

c'. Does the cake taste good to Hannah?

In fact, however, none of these sentences suggests that the speaker or Hannah has tried the cake. This is strong evidence against the presupposition account. ${ }^{19}$

In the case of the first-personal versions of (37), there may be pragmatic pressure to "locally accommodate" the presupposition in question in the antecedent of the conditional and under "might," respectively. This could explain its failure to project at least in these sentences (Anand and Korotkova 2018: 61). But we don't know how to tell a similar story about the third-personal sentences. For comparison, the factive presupposition of "find out" may be accommodated locally in "If $I$ find out that Peter cheated, I'll be disappointed." But it projects straightforwardly in "If Hannah finds out that Peter cheated, she'll be disappointed."

Another line of response would be that the PPTs in (37) receive a (futuredirected) episodic reading, where the acquaintance requirement is entailed rather than presupposed and therefore doesn't project. $^{20}$ But following Anthony (2016: 690 ), we can force the stative reading by adding restrictor when-clauses such as "when she's just brushed her teeth." These clauses operate by adding constraints to our restrictor disp, which features only in the stative reading. Even with these added clauses, the sentences in (37) don't suggest that the speaker/Hannah has tried the cake. For instance, it seems fine to say "I don't know if Hannah ever tried the cake, but if the cake tastes good to her when she's just brushed her teeth, then she's an exception." 21

Anand and Korotkova (2018: §4) propose a version of the presupposition account that faces a further challenge. They hold that (1) features an implicit evidential restriction (in the spirit of von Fintel and Gillies 2010) that requires "direct knowledge" of the proposition expressed. The presupposition TRIED arises, on their view, because direct knowledge is impossible to obtain unless one has tried the cake. But consider an amnesiac who has tried the cake. He remembers having tried the cake, but unfortunately, he can't remember whether he liked it. He asks a friend

\footnotetext{
19 The case of (37c) is subtle. Utterances of this sentence don't suggest that the speaker has tried the cake; they merely suggest that the speaker either fails to recall the taste of the cake while having tried it or fails to recall whether she tried it. This gives rise to an acquaintance requirement only on the contextual assumption that the speaker recalls whether she tried the cake. A known amnesiac, for instance, could properly ask this question even if she hasn't tried the cake.

20 A reviewer worries that, contrary to our analysis of the episodic reading, the acquaintance requirement does project in e.g. (37a) on a future-directed episodic reading, noting the oddity of "If the cake tastes good to Hannah, I'll make another one; even though I know she won't try it" when read episodically. But, in our view, the oddity here doesn't result from an acquaintance requirement but from the fact that it is odd to use indicative conditionals with knowingly false antecedents. If you know that Hannah won't try the cake, then you know that there is no future event of Hannah enjoying the cake, and hence you know that the antecedent is false on the future-directed episodic reading. The sentence "If the cake tastes good to Hannah, I'll make another one; even though I don't know whether she'll try it" sounds fine to us, suggesting that there is no acquaintance requirement.

21 Intuitions may be even clearer for counterfactual conditionals like "If the cake tasted good to Hannah when she's just brushed her teeth, then she would be an exception." Acquaintance doesn't seem required, and yet presuppositions seem to project in counterfactual conditionals (witness "If Hannah quit smoking, her mother would be happy").
} 
whether she remembers whether he liked the cake, and she responds that he did. It seems fine for the amnesiac now to assert (1), at least assuming that the friend is trustworthy. This is despite the fact that the amnesiac knows that the cake tastes good to him from testimony and hence despite the fact that he doesn't have direct knowledge of this proposition thereby violating the alleged evidential restriction.

\subsection{The epistemic account}

Consider lastly what we'll call the epistemic account of the acquaintance requirement. This account starts out with the following counterfactual.

CF1 The speaker of (1) wouldn't know that she has the relevant gustatory dispositions if she hadn't tried the cake.

According to the epistemic account, assertions of (1) thus sound bad because you shouldn't assert what you don't know, due to the knowledge norm of assertion. ${ }^{22}$

The epistemic account easily explains all of the data considered so far. The acquaintance requirement comes out as uncancellable, as it should, because one cannot properly cancel the requirements of the norms of assertion (e.g. Williamson 1996: 506-507; Ninan 2014: 303). The epistemic account can also be extended to account for an acquaintance requirement on outright belief if we adopt a knowledge norm of outright belief as a correlate of the knowledge norm of assertion (e.g. Williamson 2000; Sutton 2005; Huemer 2007). Embedding data are unproblematic because even given the knowledge norm, assertions of the complex sentences in (37) only require knowledge of the complex proposition expressed. They don't require knowledge that the cake tastes good to you (Ninan 2014: 304). The amnesiac's assertion comes out fine because he knows that the cake tastes good to him from testimony. ${ }^{23}$

The epistemic account handles the third-personal sentence (35) as well (pace Anand and Korotkova 2018: 62-63). We just need to add the following counterfactual as a further assumption.

CF2 The speaker of (35) wouldn't know that Hannah has the relevant gustatory dispositions if Hannah hadn't tried the cake.

Given CF2, the speaker will violate the knowledge norm of assertion when Hannah hasn't tried the cake. To motivate CF2, consider the ways in which we typically come to know what other people like. It's easy to see that they all require

\footnotetext{
22 Ninan (2014) defends an epistemic account with respect to bare PPTs, while remaining non-committal with respect to relativized PPTs. He suggests a principle similar to CF1, according to which acquaintance is only "normally" (302) required for taste knowledge. We think this is too weak because it would leave the acquaintance requirement cancellable. After all, inferences based on normalcy assumptions are defeasible and thus precisely the kinds of inferences that should be cancellable. Stronger principles, according to which it is plainly impossible to acquire taste knowledge without acquaintance, seem unmotivated (see Hopkins 2011: 141-142; Ninan 2014: 307; Franzén 2018: 674-675).

23 Ninan (2014: 305-306) convincingly responds to a further worry from future tense sentences. See e.g. Benton and Turri (2014) and Giannakidou and Mari (2018) for more general theories confirming his response.
} 
acquaintance on the part of the third party, Hannah. One possible source of knowledge is Hannah's testimony. For someone's testimony to bestow us with knowledge, the speaker needs knowledge herself. ${ }^{24}$ Thus, Hannah will have to know that the cake tastes good to her and, by CF1, she wouldn't know this unless she had tried the cake. Another possible source of knowledge is that we observe Hannah enjoy the food. This requires acquaintance on her part too. Other sources of knowledge may be available in principle, but they are plausibly too far-fetched to threaten the truth of CF2.

Promising as it may be, the epistemic account faces concerns. First, there seem to be situations where acquaintance is not the only plausible way to acquire taste knowledge and yet the acquaintance requirement seems in place. This is easy to see in cases where we are familiar with the type of cake in question and now assess the gustatory properties of a specific token. Suppose, for instance, that you've baked a marble cake. You've done this many times before, and you always liked the result. You've used the same recipe you always use, and you know that you did everything correctly and that all the ingredients were fine. Now the cake is done, and it's sitting in front of you. Given all your background knowledge, you should know that you are disposed to enjoy the cake from your previous experience with the other cakes you made. Utterances of (1), however, still sound problematic before you tried the cake ("will" and "would" sentences sound better). This is puzzling on the epistemic account because the knowledge norm should be satisfied. ${ }^{25}$

Second, the following sentence sounds odd.

(38) The cake probably tastes good to me, I haven't tried it though.

Better: The cake will/would probably taste good to me. I haven't tried it though.

The epistemic account doesn't explain this. Even given the knowledge norm, proper assertions of (38) don't require that I know that the cake tastes good to me. If anything, they require that I know that the cake probably tastes good to me. Given the dispositional analysis, we need the following counterfactual to derive an acquaintance requirement.

CF1* The speaker of (38) wouldn't know that she probably has the relevant gustatory dispositions if she hadn't tried the cake.

This counterfactual, however, doesn't look very plausible. For instance, knowledge of ingredients, experience with similar food and observations of other people's gustatory reactions can easily make it probable that I have certain gustatory dispositions even if these factors don't suffice to yield knowledge of these dispositions.

To respond, one might appeal to the previously distinguished episodic reading, where acquaintance is entailed. On this reading, (38) comes out as problematic, as it should (see below). However, a principle of charity should suppress this problematic

\footnotetext{
24 See Lackey (1999) for possible exceptions to this general principle.

25 Thanks to Dan López de Sa for pressing us on this point.
} 
reading in favor of the stative reading, on which the sentence should be perfectly fine, given the epistemic account.

The same problem arises for past tense sentences. The following sounds odd.

(39) The cake probably tasted good to me before it went off. I never tried it though.

Better: The cake would probably have tasted good to me before it went off. I never tried it though. ${ }^{26}$

Once more, the epistemic account doesn't explain this. For I can easily come to know that I probably had the unrealized disposition to enjoy the cake even if I never tried the cake. As before, (39) comes out as problematic on the episodic reading, where acquaintance is entailed (see below). But this won't suffice to explain the data, for charity should lead us to choose the stative reading instead. Moreover, we saw earlier that the "before"-clause normally triggers this reading anyway. ${ }^{27}$

In sum, all presented accounts face serious concerns. In what follows, we present what we take to be a more promising account. Notice that more could be said on behalf of the accounts discussed so far. For instance, intuitions about (37), (38) and (39) may not be entirely stable, and it may be worthwhile to explore them in an experimental setting. Notice also that much of what we have to say below is in principle compatible with the accounts discussed so far and that it might be worthwhile to explore more ecumenical positions. We'll leave this for another occasion.

\section{The entailment account}

We've assumed so far that the proposition expressed by (1) doesn't entail that the speaker has tried the cake. This was the result of the dispositional interpretation of the implicit quantifier $\mathrm{Q}$ and the restrictor $\mathrm{r}$. What if we interpret these elements differently such that they entail acquaintance? We'll explore this option in what follows.

Our basic suggestion will be that taste sentences don't ascribe just dispositions, but what we'll call tendencies, where a tendency is a disposition that has been manifested.

(40) The cake tastes good to me. $(=(1))$

TEND[tend(e); tastes-good-to(the cake, me, e)]

I tend to get gustatory pleasure when I eat the cake.

As in the case of DISP and disp, there is a question of how to interpret "TEND" and "tend" to arrive at the desired truth-conditions. Given that tendencies entail

\footnotetext{
26 See Anand and Korotkova (2018: 59) for related intuitions.

27 A parallel worry may arise from the oddity of future tense sentences like "The cake will probably taste good to me when it's done, but I'm not going to try it." A reviewer judges this sentence to be odd, and Anand and Korotkova (2018: 61) judge a closely related sentence to be odd (their (15b)). Notice that intuitions may shift when we replace the relativized PPT with a bare PPT (see Ninan 2014: 305).
} 
dispositions, a proper response here requires a proper analysis of dispositions, which is not our present concern. For now, we'll just assume that there is some interpretation that gives us what we want, though we are fully aware that more will have to be said eventually.

Given this analysis, the acquaintance requirement for (1) is immediately explained as an entailment of the proposition expressed. On the suggested view, (1) expresses the proposition that you tend to get gustatory pleasure from eating the cake. This entails that you actually got gustatory pleasure from eating the cake and hence it entails TRIED. When this assumption fails to obtain, assertions of (1) sound bad because you shouldn't assert falsehoods. We'll call this view the entailment account of the acquaintance requirement. ${ }^{28}$

The entailment account neatly explains all of the data described so far. Consider the worries with the implicature account. Entailments can't be cancelled, and they are equally present in thought as in speech, as they should be. Consider next the problems with the expressivist account. The entailment account easily explains the acquaintance requirement on the third party in third-personal taste sentences because, on this view, third-personal sentences say that the cake tends to cause gustatory pleasure in Hannah, and hence they entail that Hannah manifested the respective disposition. Recall also the worries with the presupposition account. Entailments differ from presuppositions precisely in that they don't survive in the indicated embeddings. Notably, they don't survive either in embeddings under "will" and "would," where instead they are temporally and modally displaced. ${ }^{29}$ Our amnesiac's assertion of (1) comes out fine too because given that he has tried the cake and liked it, he has the required tendency, and he knows that he has it from testimony.

Consider lastly the worries with the epistemic account, which require a slightly more detailed discussion. The entailment account easily explains why the acquaintance requirement for (1) remains when the speaker has baked the cake for the hundredth time. This is because the proposition expressed still entails that the speaker has tried the cake. Thus, the proposition expressed will be false (and, hence, unknown) before the speaker has tried the cake.

Consider now the "probably" sentences (38) and (39). The entailment account explains their infelicity as follows. The respective first half of these sentences entails that the speaker probably tried the cake. After all, the probability operator is plausibly closed under the relevant entailments: if probably: $p$, and p entails $q$, then probably: q. The sentences thus sound off just as "I probably tried the cake. I never tried it though" does. We can stay neutral on how the oddity of the latter sentence is

\footnotetext{
${ }^{28}$ On an alternative version of the entailment account, (1) expresses the proposition that the speaker tried the cake and liked it (no dispositions involved), which trivially entails TRIED. This view would be mistaken, as is evident from the fact that we sometimes change our tastes. When I have changed my taste, the indicated proposition may be true even if it is now false to assert (1).

29 We can still explain the disjunctive requirement in the case of (37c) (footnote 19). If the speaker recalled that she hasn't tried the cake, the question would be pointless because she would know the answer already ("No"). The question therefore suggests that the speaker doesn't recall that she hasn't tried the cake. This means that she either recalls that she has tried the cake, while failing to recall what it tasted like, or that she fails to recall whether she tried it.
} 
explained, though the knowledge norm of assertion is a natural starting point. You arguably can't know that not-p when you also know that $\mathrm{p}$ is probable.

Analogous stories can be told about sentences where "probably" is replaced by other epistemic terms such as "must," "possibly," "maybe," "obviously," "certainly" and "apparently." Such sentences also sound odd (see Anand and Korotkova 2018: 59). To explain this, we just need to assume that relevant closure principles hold in each case. ${ }^{30}$

One may worry that this account of "probably" sentences overgenerates. The following sentence sounds fine.

(41) The cake might taste good to me. I haven't tried it though.

The entailment account may seem to predict otherwise because closure inferences of the following type should be allowed in the present context: if might: $p$, and $p$ entails q, then might: q. Thus, (41) should sound as odd as "I might have tried the cake. I haven't tried it though." In response, notice that present tense "might" sentences are often future directed (Condoravdi 2002). For instance, it is perfectly fine to say "I might try the cake, but I haven't tried it yet (and I'm not trying it right now)." This is because the speaker merely conveys that she might try the cake in the future. The same is going on, we think, in (41), where the speaker also conveys that the cake might taste good to her in the future and thus that she might try it in the future. $^{31}$

An important objection remains. If (1) entails that I have tried the cake, then the negation of (1) cannot also entail this. Otherwise, it would be necessarily true that I've tried the cake (revisionary logics aside). This means that, on the entailment account, the acquaintance requirement shouldn't arise for the negation of (1). In fact, however, it seems that it does. The following sentence, for instance, is clearly odd.

(42) The cake doesn't taste good to me, I haven't tried it though. ${ }^{32}$

The entailment account similarly predicts that if I haven't tried the cake, then this should be a good reason to deny (1) and hence to assert its negation. After all, if I know that an entailment of a given proposition is false, this is generally a good (epistemic) reason to assert its negation. In fact, however, the following sounds odd.

\footnotetext{
30 Anand and Korotkova (2018: 58) rightly observe that all of these sentences become fine when we replace the relativized PPT with a bare PPT. This asymmetry remains to be explained. See Pearson (2013: 142-144) for one attempt, and Ninan (2014: 300-301) for convincing criticism. Anand and Korotkova's (2018: 69-70) account of the asymmetry predicts that e.g. "The cake must taste good to me" presupposes that the speaker's direct knowledge directly settles whether the cake tastes good to her. This seems wrong because our amnesiac from above can properly assert this sentence based on his friend's testimony. Indeed, Anand and Korotkova themselves informally suggest that, in the absence of acquaintance, this sentence may only trigger "a sense of forgetfulness" (69). Their theory, however, predicts presupposition failure.

31 Our intuitions about "The cake might taste good to me, but I never tried it and I never will" are shaky. Anand and Korotkova (2018: 61) judge a past tense version of this sentence to be bad, in line with our account.
}

32 See Ninan (2014: 294-295) for this concern with entailment accounts in the domain of bare PPTs. 
(43) I haven't tried the cake; therefore, it doesn't taste good to me.

Finally, consider a situation where I satisfy all the requirements for the truth of (1) except that I haven't tried the cake. In such a situation, (1) should become true once I try the cake. Thus, after I tried the cake, it should be fine to say:

(44) The cake didn't taste good to me, but now it does.

In fact, though, this sentence sounds clearly odd in the context described. ${ }^{33}$

To respond, notice the familiar distinction between wide-scope and narrow-scope negation. Given our quantificational analysis of (1), these different negations yield different truth-conditions, and a problem arises for the entailment account only on the wide-scope reading. Our hypothesis is that this reading is unavailable, or difficult to get, and that the above sentences sound problematic for this reason.

For comparison, consider sentences with implicit generic quantifiers such as the following sentences featuring bare plurals.

Sparrows have a brown cap.

(46) Sparrows don't have a brown cap.

Leslie (2008: 38; see also Hoeltje 2017: 103) argues that not only the first but also the second sentence is standardly understood as a generic, meaning that the negation is standardly understood as taking narrow scope, along the following lines.

GEN [ $\mathrm{x}$ is a sparrow; not: $\mathrm{x}$ has a brown cap]

It seems very hard to get the following reading.

Not: GEN[x is a sparrow; $x$ has a brown cap]

Leslie doesn't explain why this is so, and we can't go into this here either. What is relevant for our purposes is just that there is precedent for our claim that some quantifiers make it very hard for negations to take wide scope. Just like in the case of generics, the negation in taste sentences may only be able to take narrow scope, along the following lines:

The cake doesn't taste good to me.

TEND[tend(e); not: tastes-good-to(the cake, me, e)]

I tend not to get gustatory pleasure when I eat the cake.

The acquaintance requirement remains because, given this logical form, acquaintance is still entailed. You can tend not to enjoy the cake only if you manifest the underlying disposition, and this, in turn, requires that you tried the cake.

\footnotetext{
33 Notice that the acquaintance requirement disappears in negated taste sentences featuring an episodic reading, as it should on our account. For instance, “The cake didn't taste good to me because I didn't try it," "The cake doesn't taste good to me right now because I'm not eating it at the moment" and "The cake won't taste good to me because I won't try it" all seem to have a true episodic reading. The sentences (42) to (44) above are odd on an episodic reading for independent reasons. For instance, the "though" in (42) and the "therefore" in (43) would be entirely out of place, and the second half of (44) would be trivially false in the suggested context, because after I tried the cake, there is no present cake eating event anymore. Notice that (44) seems to a have a fine reading when uttered while eating the cake..
} 
Admittedly, the relevant generics can receive wide-scope interpretations in special contexts.

A: Sparrows have a brown cap.-B: Sparrows don't have a brown cap. There are house sparrows and tree sparrows, and only the latter have a brown cap!

This is not a problem though because the same seems to be true for taste sentences.

A: The cake tastes good to Hannah.-B: The cake doesn't taste good to Hannah. She hasn't even tried it!

So if anything, these observations confirm the suggested analogy because they suggest that generics and taste sentences pattern in relevantly similar ways. ${ }^{34}$

Our account may still predict that sentences like "It is false that the cake tastes good to me" or "It is not the case that the cake tastes good to me" come out as true when I haven't tried the cake. We have no firm intuitions about these clunky and marginal sentences, though, and so we think it's fine to endorse these theoretical commitments. Though some unanswered questions about the entailment proposal remain, we turn now to show how our approach can be extended to the realm of character traits. ${ }^{35}$

\section{Character traits}

Consider sentences ascribing character traits such as

$$
\text { Hannah is brave. }(=(13))
$$

Initially, it may seem natural to analyze this sentence dispositionally such that Hannah is brave iff she is disposed to act bravely when she encounters situations that call for bravery (see footnote 7). This analysis, however, faces an immediate challenge, for it seems that assertions of (13) are problematic if Hannah hasn't manifested bravery before. Alston (1970: 62) states this requirement as follows (see also footnote 8 ).

[U]nless $\mathrm{P}$ has obeyed some orders, it cannot be correct to call him obedient [...]. A person who has never obeyed any orders might be correctly called "potentially obedient," "an obedient type," or "a person who would be

\footnotetext{
34 Once more, bare PPTs may behave differently. Ninan (2014: 298) suggests that the following sounds bad. "The lobster rolls at Neptune Oyster aren't tasty - I haven't even tasted them!"

35 One further worry with the entailment account is that the entailment relation to TRIED is too strong. For instance, it may seem fine to say "The cake doesn't taste good to me" when you only know that the cake contains an ingredient that you strongly dislike (e.g. cloves). Our tentative response is, first, that we're unsure about the intuitions. To us, it still sounds better to say "The cake won't/wouldn't taste good to me." Second, this could be a case of pragmatically unobjectionable linguistic laziness or maybe overstatement. Notice the importance here of focusing on languages like English where there is a comparatively sharp distinction between future and present tense. Intuitions are less clear in languages like German where one and the same sentence can often receive both a present and a future reading, and where a superficially present tense sentence can thus seem fine because it's heard as future directed.
} 
obedient if he had the chance"; but we could not be justified in terming him "obedient" tout court. The occurrence of some instance of the correlated manifestation category is a necessary, though not sufficient, condition for the application of the trait term.

Alston (and others) primarily focus on the requirement that the relevant disposition has to have been manifested to properly ascribe the trait in question. For presentational purposes, we'll focus instead on an immediate consequence of this requirement. Dispositions normally have stimulus conditions, and they manifest themselves only when these conditions obtain. ${ }^{36}$ Thus, if proper ascriptions of e.g. braveness require manifestations of braveness, they also require that the subject in question once faced the stimulus conditions for acting bravely, i.e. she must have faced a situation that called for bravery. Our question in what follows will be how this latter requirement-the stimulus requirement, as we will call it-arises.

The options seem to be more or less the same as in the case of taste. Dispositionalists can appeal to conversational implicatures, semantic presuppositions and epistemic norms of assertion. Only expressivism no longer looks like an option because ascriptions of character traits don't seem to express anything other than a belief in the proposition expressed. The alternative is to abandon the dispositional analysis and to replace it e.g. with an analysis in terms of tendencies. In what follows, we'll argue that, since the data are parallel to the case of taste, the appeal to tendencies is most promising.

To begin with, notice the familiar ambiguity between stative and episodic readings in past and future tense sentences ascribing character traits.

Hannah was brave.

Hannah will be brave.

These sentences can suggest either that Hannah acted or will act bravely on a specific past or future occasion or that her standing properties have or will change. We can once more capture this ambiguity if we introduce the property brave(Hannah, e), which applies just in case e is an event of Hannah acting bravely. The two readings can now be described as follows, where $\mathrm{e}_{\text {past }}$ and $\mathrm{e}_{\text {fut }}$ are actual past or future salient events.

(53) Hannah was brave/Hannah will be brave. $(=(51 / 52))$

Episodic: brave(Hannah, $\mathrm{e}_{\text {past }} / \mathrm{e}_{\text {fut }}$ )

Stative: Q[e is in the past/future, ...; brave(Hannah, e)]

The stimulus requirement is easily explained in the case of episodic readings, for if Hannah acted or will act bravely, there was or will be an opportunity for doing so. A past or future directed stimulus requirement is thus entailed. The question remains how to explain the stimulus requirement on the stative reading.

We begin with the options for the dispositionalist, who spells out the stative reading as follows.

$\overline{36}$ Alvarez (2017a: 85) notes potential exceptions. See also Vetter (2015). 
(54) Hannah is brave. (= (13))

DISP[disp(e); brave(Hannah, e)]

Hannah is disposed to act bravely when a situation calls for bravery.

Our discussion will be brief, and we will basically just point out that the intuitive data are parallel to the case of relativized PPTs. Readers may return to the discussion of relativized PPTs for details.

Consider an account where the stimulus requirement is a conversational implicature. Such an account is problematic because the stimulus requirement doesn't seem cancellable. The following sentence, for instance, sounds odd.

Hannah is brave, though she never encountered a challenging situation in her life.

Focusing on the manifestation rather than the stimulus requirement, Hampshire (1953: 6) similarly points out that "[o]ne cannot normally say that someone is ambitious and generous, while denying that he has ever either acted or calculated in a generous and ambitious manner." Furthermore, it seems not only odd to assert that Hannah is brave but also to outright believe this when Hannah never had the opportunity to act bravely.

Consider the idea that the stimulus requirement is a presupposition. This is problematic because the alleged presupposition fails to project in relevant embeddings. The following sentences no longer suggest that Hannah had the opportunity to act bravely.
a. If Hannah is brave, then I want her in my unit.
b. Hannah might be brave.
c. Is Hannah brave?

Anand and Korotkova's (2018) presupposition account in terms an evidential restriction to direct knowledge cannot be transposed to the domain of character traits (as they would readily acknowledge), for you can easily assert (13) if you know from testimony that Hannah consistently acted bravely whenever the opportunity arose.

This leaves us with the epistemic account. This account is problematic because, first, there are cases where we are in a position to know that a subject has a disposition, and yet we cannot properly ascribe the corresponding character trait to them. With respect to regular dispositions, Alvarez (2017a: 75) notes that "it makes sense to say of this tumbler that it is fragile because it is made of glass and glass is fragile." She goes on to note that "this is not so with character traits for, even if we discovered reliable correlations between certain character traits and, say, genetic make-up, or neural features, or upbringing, or nationality, etc., we still could not attribute the trait to the person independently of whether she had manifested it" (84). Intuitions may be weaker here than in the case of taste, if only because the scenarios Alvarez envisages are so remote. The mentioned correlations, at least as far as we know them to date, come nowhere close to being reliable enough to support knowledge. We still think that Alvarez is on to something (see also her remarks on p. 80). 
Second, the epistemic account makes it puzzling why the following sentences sound off.

(57) Hannah is probably brave; but she never encountered a challenging situation in her life.

Better: Hannah would probably be brave, but she never encountered a challenging situation in her life.

(58) Hannah was probably brave before we drugged her with the wimp-drug, but she never encountered a challenging situation in her life.

Better: Hannah would probably have been brave before we drugged her with the wimp-drug, but she never encountered a challenging situation in her life.

Alvarez (2017a: 81) expresses related intuitions when she writes that "the claim that someone who has never manifested courage in any way whatsoever is, for all we know, a courageous person is a claim that is, if not contradictory, at least in search of meaning." She considers "for all we know" instead of "probably," but it is clear from the context that she would say the same about "probably." (Notice that, even though "for all we know" is closer to "might" in many respects, it doesn't have the same potential for future-directness.)

Taken together, these considerations put pressure on the dispositional analysis. We thus suggest replacing this analysis by an analysis in terms of tendencies.

Hannah is brave. $(=(13))$

TEND[tend(e); brave(Hannah, e)]

Hannah tends to act bravely when a situation calls for bravery.

The stimulus requirement comes out as an entailment of the proposition expressed, and the presented data can be explained as discussed before in the domain of taste.

Indeed, Alvarez (2017a) suggests just such an account (see also Alvarez 2017b: 127-128). She says that "behaviour (broadly conceived) within the range typical of a character trait is necessary for one to have the character trait" (83). ${ }^{37}$ She notes further that this is supposed to be "consistent with thinking of character traits as dispositional" (85). She doesn't specify exactly how to achieve this consistency, but the natural thought is that traits are dispositions that have been manifested before. Alvarez also suggests the label "tendency" (85) to capture these manifested dispositions, which inspired our own terminological choice above. ${ }^{38}$

Alvarez bases her case for the tendency view primarily on the indicated types of criticism of the epistemic account. We can see now that the case for her position is stronger than she makes it out to be because dispositionalist appeals to conversational implicature and presupposition don't fare any better. We are also

\footnotetext{
37 She even claims that manifestations are "constitutive" (79) for having a character trait.

38 Notice that the tendency view must be distinguished from the "summary view" (see e.g. Miller 2014: 18 for references and criticism; see also Alvarez 2017a: 80n23). On the tendency view, character traits depend on one's present dispositions along with previous manifestations. On the summary view, they depend just on the previous manifestations.
} 
familiar with a pressing challenge to the entailment account and with how to answer it. ${ }^{39}$ Consider

(60) Hannah isn't brave.

This sentence seems to come with a stimulus requirement in that we can properly assert it only if Hannah once had the opportunity to act bravely (and, in this case, failed to act bravely). Similarly, the following sounds off, which seems puzzling on the tendency account.

(61) Hannah never had the opportunity to show braveness. Therefore, she isn't brave.

Brandt (1970: 26) confirms this latter intuition: "Suppose we knew a given person had lived a very sheltered life and had never been required to act in the face of a serious threat. [...] Would we infer of such a person that he cannot be courageous? Surely not."

Finally, suppose Hannah satisfied all the braveness conditions except for the stimulus requirement and now acted bravely for the first time. Contrary to the entailment account, we cannot properly assert the following sentence subsequent to her first brave act.

(62) Hannah wasn't brave, but now she is.

To respond, we can point out once more that this behavior is familiar from generics, where negations standardly take narrow scope. (60) is read as

TEND[tend(e); not: brave(Hannah, e)]

Hannah tends not to act bravely when a situation calls for bravery.

The stimulus requirement remains in place for this reason. Once more, special contexts can trigger a wide-scope reading.

A: Hannah is brave.-B: Hannah isn't brave. She never encountered a challenging situation in her life!

As we saw, this is parallel to the case of generics.

In sum, a strong case can be made for a tendency account of character traits, and such an account has been independently suggested in the literature. This shows that the notion of a tendency is independently useful and not just an ad hoc invention to deal with the acquaintance requirement.

\section{General upshots}

Ascriptions of relativized gustatory properties come with an acquaintance requirement while ascriptions of character traits come with a stimulus requirement. We can see now that both these requirements are properly classified as a stimulus

39 Alvarez (2017a: 79-85) addresses some further potential challenges. 
requirement. Tendencies, just like dispositions, come with certain stimulus conditions. In the case of relativized gustatory properties, these are occasions where one tries the food in question. In the case of braveness, they are opportunities for acting bravely. In each case, these stimulus conditions must have occurred to properly ascribe the relevant property, giving rise to a stimulus requirement. In each case, there is also a corresponding manifestation requirement. In the case of unnegated/negated taste sentences, you must have enjoyed/failed to enjoy the cake while eating it. In the case of braveness ascriptions/denials, you must have acted bravely/failed to act bravely when the opportunity arose. These unifying observations put pressure on any account of the acquaintance requirement that fails to generalize to other stimulus or manifestation requirements. Expressivist accounts and views in terms of evidential presuppositions, as applied to relativized PPTs, have a hard time here.

We have offered a unified account of the acquaintance requirement and the stimulus requirement in the domain of character traits. We have argued that the acquaintance requirement is best explained as an entailment, and we went on to show that analogous considerations strengthen the case for an entailment account of the stimulus requirement. In each case, the relevant entailment can be generated by replacing dispositions with tendencies. Indeed, tendencies may play an even larger role. Alvarez (2017b), for instance, suggests that desires should be understood as tendencies rather than dispositions, habituals such as "Hannah smokes" are another potential domain of application (Krifka et al. 1995: 54; Alvarez 2017b: 127-128) and so are the numerous experiential predicates mentioned in the introduction. We'll leave this for another occasion.

Acknowledgements We are grateful to Brendan Balcerak Jackson, Delia Belleri, Jochen Briesen, Miguel Hoeltje, Katharina Felka, Nils Franzén, Dan López de Sa, Jonathan Schaffer, Alex Steinberg, Barbara Vetter, Emanuel Viebahn, Timothy Williamson, Dan Zeman and an anonymous reviewer for very helpful comments. We would also like to thank philangling as well as audiences in Barcelona, Berlin, Erlangen, Hamburg, Skálholt, Tübingen and Warsaw. The study was funded by Deutsche Forschungsgemeinschaft (Grant Number DI 2172/1-1). Open Access funding provided by Projekt DEAL

Open Access This article is licensed under a Creative Commons Attribution 4.0 International License, which permits use, sharing, adaptation, distribution and reproduction in any medium or format, as long as you give appropriate credit to the original author(s) and the source, provide a link to the Creative Commons licence, and indicate if changes were made. The images or other third party material in this article are included in the article's Creative Commons licence, unless indicated otherwise in a credit line to the material. If material is not included in the article's Creative Commons licence and your intended use is not permitted by statutory regulation or exceeds the permitted use, you will need to obtain permission directly from the copyright holder. To view a copy of this licence, visit http:// creativecommons.org/licenses/by/4.0/.

\section{References}

Alston, W. P. (1970). Toward a logical geography of personality. Traits and deeper lying personality characteristics. In H. E. Kiefer \& M. K. Munitz (Eds.), Mind, science, and history (pp. 59-92). Albany, NY: State University of New York Press. 
Alvarez, M. (2017a). Are character traits dispositions? Royal Institute of Philosophy Supplement, 80, 69-86.

Alvarez, M. (2017b). Desires, dispositions and the explanation of action. In J. A. Deonna \& F. Lauria (Eds.), The nature of desire (pp. 119-135). Oxford: Oxford University Press.

Anand, P., \& Korotkova, N. (2018). Acquaintance content and obviation. In U. Sauerland \& S. Solt (Eds.), Proceedings of Sinn und Bedeutung 22 (pp. 55-72).

Anthony, A. (2016). Experience, evaluation and faultless disagreement. Inquiry, 59(6), 686-722.

Benton, M. A., \& Turri, J. (2014). Iffy predictions and proper expectations. Synthese, 191(8), 1857-1866.

Brandt, R. (1970). Traits of character. A conceptual analysis. American Philosophical Quarterly, 7(1), 23-37.

Budd, M. (2003). The acquaintance principle. British Journal of Aesthetics, 43(4), 386-392.

Bylinina, L. (2017). Judge-dependence in degree constructions. Journal of Semantics, 34(2), 291-331.

Cappelen, H., \& Hawthorne, J. (2009). Relativism and monadic truth. New York, NY: Oxford University Press.

Chomsky, N. (1972). Studies on semantics in generative grammar. The Hague: Mouton.

Condoravdi, C. (2002). Temporal interpretation of modals. Modals for the present and for the past. In D. I. Beaver (Ed.), The construction of meaning (pp. 59-88). Stanford, CA: CSLI Publications.

Douven, I. (2010). The pragmatics of belief. Journal of Pragmatics, 42, 35-47.

Egan, A. (2014). There's something funny about comedy. A case study in faultless disagreement. Erkenntnis, 79(1), 73-100.

Franzén, N. (2018). Aesthetic evaluation and first-hand experience. Australasian Journal of Philosophy, 96(4), 669-682.

Giannakidou, A., \& Mari, A. (2018). A unified analysis of the future as epistemic modality. Natural Language \& Linguistic Theory, 36(1), 85-129.

Grice, H. P. (1989). Studies in the way of words. Cambridge, MA: Harvard University Press.

Hampshire, S. (1953). Dispositions. Analysis, 14(1), 5-11.

Hoeltje, M. (2017). Generics and ways of being normal. Linguistics and Philosophy, 40(2), 101-118.

Hopkins, R. (2000). Beauty and testimony. Royal Institute of Philosophy Supplement, 47, 209-236.

Hopkins, R. (2001). Kant, quasi-realism, and the autonomy of aesthetic judgement. European Journal of Philosophy, 9(2), 166-189.

Hopkins, R. (2011). How to be a pessimist about aesthetic testimony. Journal of Philosophy, 108(3), $138-157$.

Huemer, M. (2007). Moore's paradox and the norm of belief. In S. Nuccetelli \& G. Seay (Eds.), Themes from G.E. Moore. New essays in epistemology and ethics (pp. 142-157). Oxford: Oxford University Press.

Klecha, P. (2014). Diagnosing modality in predictive expressions. Journal of Semantics, 31(3), 443-455.

Krifka, M., Pelletier, F. J., Carlson, G. N., et al. (1995). Genericity. An introduction. In G. N. Carlson \& F. J. Pelletier (Eds.), The generic book (pp. 1-124). Chicago, IL: The University of Chicago Press.

Lackey, J. (1999). Testimonial knowledge and transmission. The Philosophical Quarterly, 49(197), $471-490$.

Leslie, S.-J. (2008). Generics. Cognition and acquisition. The Philosophical Review, 117(1), 1-47.

MacFarlane, J. (2014). Assessment sensitivity: Relative truth and its applications. Oxford: Oxford University Press.

Manley, D., \& Wasserman, R. (2008). On linking dispositions and conditionals. Mind, 117(465), 59-84.

Miller, C. B. (2014). Character and moral psychology. Oxford: Oxford University Press.

Mothersill, M. (1984). Beauty restored. Oxford: Clarendon Press.

Ninan, D. (2014). Taste predicates and the acquaintance inference. Proceedings of SALT, 24, 290-309.

Pearson, H. (2013). A judge-free semantics for predicates of personal taste. Journal of Semantics, 30(1), $103-154$.

Rudolph, R. E. (2020). Talking about appearances. The roles of evaluation and experience in disagreement. Philosophical Studies, 177(1), 197-217.

Scruton, R. (1998). Art and imagination: A study in the philosophy of mind. South Bend, IND: St. Augustine's Press.

Simion, M. (2016). Assertion: Knowledge is enough. Synthese, 193(10), 3041-3056.

Sutton, J. (2005). Stick to what you know. Noûs, 39(3), 359-396.

Vetter, B. (2015). Potentiality: From dispositions to modality. Oxford: Oxford University Press.

von Fintel, K., \& Gillies, A. S. (2010). Must...stay...strong! Natural Language Semantics, 18(4), 351-383. 
Wedgwood, R. (2012). Outright belief. Dialectica, 66(3), 309-329.

Williamson, T. (1996). Knowing and asserting. The Philosophical Review, 105(4), 489-523.

Williamson, T. (2000). Knowledge and its limits. Oxford: Oxford University Press.

Wollheim, R. (1980). Art and its objects. Cambridge: Cambridge University Press.

Willer, M., \& Kennedy, C. (Forthcoming). Assertion, expression, experience. Inquiry: An Interdisciplinary Journal of Philosophy.

Zakkou, J. (2018). The cancelability test for conversational implicatures. Philosophy Compass, 13(12), 1-14.

Publisher's Note Springer Nature remains neutral with regard to jurisdictional claims in published maps and institutional affiliations. 